Phase Determination in the Isomorphous Substitution Method Centre of Symmetry (determination of amplitude sign) Heavy atom on centre Algebraic amplitude addition (1936)

(a) Location of the heavy atom (Patterson analysis)

(b) Algebraic amplitude addition (1939)

No centre of symmetry (determination of phase angle)

(a) Location of the heavy atom.

(b) Determination of absolute value of phase angle from amplitude addition in vector diagram (1949).

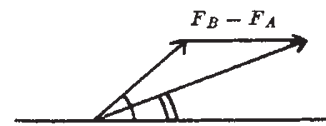

(c) Synthesis of double Fourier and resolution by geometrical considerations.

(d) Phase by anomalous scattering (1951).

$\left(c^{\prime}\right)$ Determination of all phase signs by anomalous scattering (19?).

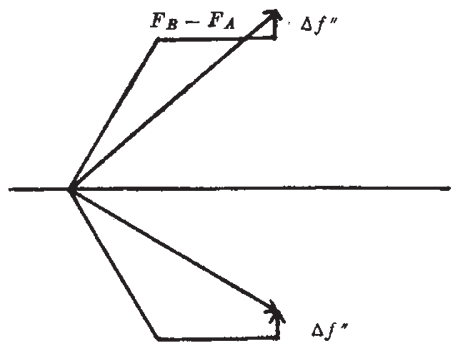

position of the two antipodes, as the right set of signs results in the actual structure of the opposite set in the inverted structure. These two structures must be separated by geometrical considerations, which require the interatomic distances to be of normal value. These spatial considerations deprive the method of much of its simplicity and beauty; the atoms no longer 'emerge' quite spontaneously from the $X$-ray data which is so striking in direct Fourier synthesis. It is therefore obvious that along these lines no discrimination is reached between the two disentangled structures. The double Fourier was used for the first time under somewhat different conditions in the structure determination of cholesterine hydriodide?, and later on, in the form just described, in the cases of strychnine sulphate/selenate and glycyltyrosine hydrochloride/bromide.

The second part of the procedure consists of the decision between the two models after the structure has been found, except for possible inversion. This determination of absolute configuration has been carried out for a compound basic ${ }^{8}$ in stereochemistry : for tertaric acid, in the form of the sodium rubidium doub le salt ${ }^{\circ}$ and the acid rubidium salt ${ }^{10}$.

Anomalous scattering of the rubidium atoms was obtained by the use of zirconium rays. Although the phase sign of one density wave would have been sufficient, the effect was observed for several reflexions. 'The phase signs of the salts of dextrorotatory tartaric acid fitted the conventional model, which consequently was proved to correspond to its real configuration.

As early as 1930, Coster proved the 111 and $1 \mathrm{II}$ reflexions of zinc sulphide are of unequal intensities for rays exciting the zinc atom. This determination of the sense of a sequence is exactly the problem we met with in the location of our reference wave and the Fourier wave of our crystal. In both cases it is the sense of a polar sequence which must be determined, and indeed can be determined by anomalous diffraction.
The method for determining absolute configuration supplies organic chemistry with a means of establishing the configurational relation between compounds which cannot be converted into each other, or in the conversion of which a Walden inversion may take place that changes the configuration into its mirror image. Investigations in this field are in progress in several laboratories.

It is surprising that, although the structure effect in zinc sulphide was known, the determination of absolute configuration was still thought for many years to be impossible.

1 Bragg, W. H., Phil. Trans. Roy. Soc., A, 215, 253 (1915).

2 Robertson, J., J. Chem. Soc., 615 (1935); 1195 (1936)

Bokhoven, C., Schoone, J. C., and Bijvoet, J. M., Acta Cryst., 4, 275 (1951).

Smits, D. W., and Wiebenga, E. H., Acta Cryst., 6, 531 (1953).

${ }^{5}$ von Laue, M., Ann. Physik, 50, 33 (1916). Coster, D., Knol, K. S., and Prias, J., Z. Phys., 63, 345 (1930). See also James, K. W., "The

- Zernike, F., Physica, 1, 689 (1934).

"Carlisle, C. H., and Crowfoot, D., Proc. Roy. Soc., A, 184, 64 (1945).

${ }^{B}$ As regards the historical role of tartaric acid in stereochemistry, see Bernal, J. D., "Science and Industry in the Nineteen Century", Chapter' 7 (Routledge and Kegan Paul, London).

- Bijvoet, J. M., Peerdeman, A. F., and van Bommel, A. J., Nature,

168, 271 (1951). Peerdeman, A. F., van Bommel, A. J., and Bijvoet,

J. M., Proc. Roy. Soc., Amsterdam, B, 54, 16 (1951).

${ }^{\circ}$ van Bommel, A. J., Proc. Roy. Soc., Amsterdam, B, 56, 268 (1953).

\section{THE QUEEN'S UNIVERSITY, BELFAST}

\section{NEW GEOLOGY BUILDING}

XHEN Queen's College, Belfast, was founded in 1847, Frederick MeCoy was appointed to the chair of geology and mineralogy. In $1854 \mathrm{McCoy}$ left Belfast for Australia, where he continued to build up his world reputation as a palæontologist and was eventually knighted. Wyville-Thompson, who succeeded him, became professor of natural history in 1860 on the amalgamation of his own Department with the Departments of Zoology and Botany. After Wyville-Thompson went to Edinburgh in 1870 and until 1909, geology continued to be taught in the combined Department. With the foundation of The Queen's University in 1909, chairs of zoology and botany and a lectureship in geology were created, Dr. A. R. Dwerryhouse being elected to the new lectureship. On his resignation in 1921, the chair of geology was re-established, and Dr. J. K. Charlesworth was appointed.

In the days of Queen's College, geology shared a common museum and lecture room. Since 1921 the Department has occupied a succession of wooden buildings, at first two army huts, later the orthopædic and later still some of tho general wards of the Ulster Volunteer Force Hospital erected in the grounds of the University in 1915. Plans were prepared in the 1930's for a new geology building, with Mr. John McGeagh as architect and Mr. (now Sir) Edward Maufe, R.A., as consultant. The outbreak of war in 1939 and the subsequent shortage of materials postponed the erection of the building until September 1950 and its completion until this year. The formal opening by Sir Edward Bailey took place on April 30.

The geology building forms the south-west wing of a group of buildings to be arranged around a large quadrangle opening to the south on to Elmwood Avenue. Hence the entrance to the geology building 


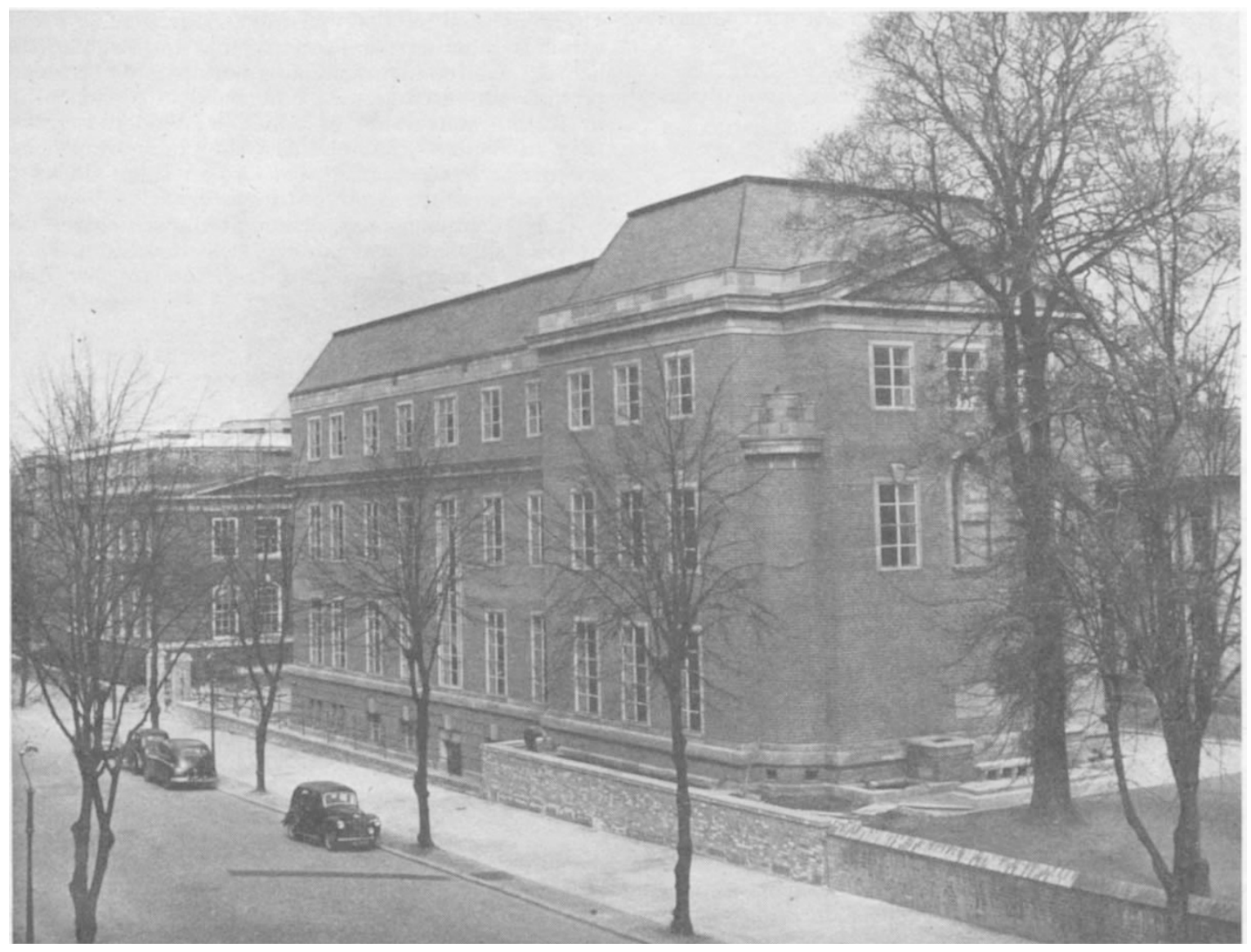

The Queen's University, Belfast. New geology building

Belfast New8-Letter

is on the north at one end of a future cloister. The exterior has been designed on clean contemporary lines and has regard for the adjacent agricultural building of Georgian style and for the traditional styles of the University district. The chief materials are Buckley Junction hand-made sand-faced bricks, Clipsham stone and green Borrowdale slates.

The building, rectangular in plan, is about $124 \mathrm{ft}$. long and 41-44 ft. wide. It has three floors, an attic, and a basement or lower ground floor. The latter, which is excavated beneath the whole site except the lecture theatre, is occupied by women's and men's cloak rooms and lavatories; by a boiler house with solid fuel fed by automatic stoking thermally controlled, and designed ultimately to heat half the buildings around the new quadrangle; by an unpacking room which receives large consignments of rocks or apparatus by a ramp from the gate leading to the agricultural court; and by a rockcutting room the ceiling of which is cork-insulated to eliminate vibration and sound from the rest of the building. A full-sized lift carries the loads to each floor, including the attic.

On the ground floor are the entrance vestibule, senior laboratory, attendant's room, demonstration lobby, lecture theatre and professor's rooms ; on the first floor the elementary laboratory, map room and library, and photographic rooms; and on the second floor the large petrology and palæontology laboratories, chemical laboratory and small lecture room. Staff and research rooms occur on each floor. The undivided attic, which extends beneath a mansard roof over one-third of the building, is well lit by circular dome lights of glass in the flat part of the roof and is ventilated by clerestory windows. It provides the research and store space of the future.

The lecture theatre, which seats 160 , has mechanical ventilation, electrically operated blinds, dimming roof lights, and a large lecture bench. Uninterrupted views are obtained of the bench, blackboards, coloured geological models, maps and projection screen. The demonstration lobby, on the line of approach to the lecture theatre, serves for the display of photographs, maps and specimens to illustrate lectures and at the same time gives added spaciousness to the entrance hall. The two supporting rectangular columns have been used for depicting the geological column in its chronological, palæontological, petrological and tectonic aspects.

The corridors, which are $8 \mathrm{ft}$. wide to provide viewing space for the numerous coloured maps, have been reduced to a minimum by placing the lecture theatre, large laboratories and library and map room at the ends of the building. The laboratories are lined along their outside walls with show-cases which fit flush under the windows and rest on drawers. In this way, a separate museum is avoided, all the material in the Department forms part of the teaching collections, and space is provided for new accessions which are immediately available for study: storerooms as such become unnecessary. The wall cases have dictated the method of heating throughout the building, which is by low-pressure hot-water panels embedded in the ceilings. J. K. CHARLESWORTH 